\title{
A study on the severity and prevention measures of COVID-19 among dental professionals in clinical practice management
}

Gotam Das ${ }^{\mathrm{a}, *}$, Shaheen Ahmed ${ }^{\mathrm{b}}$, Abdul Razzaq Ahmed ${ }^{\mathrm{a}}$, Vineet Tirth ${ }^{\mathrm{c}, \mathrm{d}}$, Soofia Jamile, Ammar Ali Muhammad ${ }^{\mathrm{f}}$, Saiful Islam ${ }^{\mathrm{g}, \mathrm{h}}$ and Amit Tirth ${ }^{\mathrm{i}}$

${ }^{a}$ Department of Prosthodontics, College of Dentistry, King Khalid University, Abha, Kingdom of Saudi Arabia

${ }^{\mathrm{b}}$ Department of Oral and Maxillofacial Surgery, Dow International Dental College, Dow University of Health Sciences, Karachi, Pakistan

${ }^{\mathrm{c}}$ Mechanical Engineering Department, College of Engineering, King Khalid University, Abha, Kingdom of Saudi Arabia

${ }^{\mathrm{d}}$ Research Center for Advanced Materials Science (RCAMS), King Khalid University Guraiger, Abha, Kingdom of Saudi Arabia

e Department of Oral and Maxillofacial Surgery, Dr Ishrat-ul-Ebad Khan Institute of Oral and Health Sciences, Dow University of Health Sciences, Karachi, Pakistan

${ }^{\mathrm{f}}$ Indus Health Network, Karachi, Pakistan

${ }^{\mathrm{g}}$ Civil Engineering Department, College of Engineering, King Khalid University, Abha, Kingdom of Saudi Arabia

${ }^{\mathrm{h}}$ Department of Geotechnics and Transportation, School of Civil Engineering, Faculty of Engineering,

Universiti Teknologi Malaysia, Johor Bahru, Malaysia

${ }^{\mathrm{i}}$ Department of Public Health Dentistry, Kothiwal Dental College and Research Center, Moradabad, India

Received 20 September 2020

Accepted 11 September 2021

\begin{abstract}
.
BACKGROUND: Medical professionals, especially dental professionals, have been adversely affected by the pandemic of COVID-19 due to an increased chance of exposure to patients because of close contact during treatments.

OBJECTIVES: This study aimed to evaluate knowledge about the disease and assess ways of precautions to be taken during the pandemic.

METHODS: A questionnaire was developed and registered at Google Forms. The study population included dental practitioners, working in hospitals and clinics. A total of 495 dental practitioners from 14 different countries across the world responded. Most dentists were aware of the required modifications in the management of patients. The points allotted for each correct/best answer by participants for a group of questions regarding each component (Knowledge, Perceptions, and Practices) were added/summed to generate an overall score for each of the three components.

RESULTS: Both univariate and multivariate analysis employed for the evaluation of results. Moreover, the total practice score was significantly associated with gender and sector of practice. Multivariable analysis model using multiple linear
\end{abstract}

*Address for correspondence: Gotam Das, Assistant Professor, Department of Prosthodontics, College of Dentistry, King Khalid
University, Abha 61411, Kingdom of Saudi Arabia. Tel.: +966 593280973; E-mail: drgotam2000@gmail.com. 
regressions was formulated by including those variables which were significant at the univariate stage. Hence, the practice sector was the only variable found to be significantly associated with the total knowledge score $(p$-value $<0.05)$. Conclusion: This study, based on our experience and relevant guidelines and research, introduces essential knowledge about COVID-19 and infection in dental settings.

Keywords: Awareness, pandemic, hygiene practice, infection control, coronavirus

\section{Introduction}

The rapidly climbing outbreak of COVID-19 caused by severe acute respiratory syndrome Coronavirus-2 (SARS-CoV-2) exhibits a serious global concern that is affecting general health of medical professional, overall healthcare systems, and the global economy. The first patient with pneumonia of an unknown cause that resembled viral pneumonia was reported in Wuhan, China on December 31, 2019 [1]. This pneumonia was a result of secondary pulmonary infection, attributed to 2019 novel Coronavirus (2019-nCoV) [2] and officially termed SARSCoV-2 [3]. As the COVID-19 outbreak progressed rapidly across the world, the World Health Organization (WHO) declared a global pandemic on March 11, 2020. COVID-19 has affected more than 164 million people globally with over 3412032 confirmed deaths in about 216 countries and territories as of May 21, 2021, therefore posing a serious and alarming public health concern [4]. Strict measures are being extensively undertaken to mitigate the community transmission of COVID-19 through social distancing, quarantines, lockdowns, travel restrictions, and the requisite of wearing facemasks in public [5].

The transmission patterns of SARS-CoV-2 propose that respiratory droplets and direct contact are the main routes of transmission [6]. With this concept, the possibility of aerosol transmission in a closed environment with high concentrations of vital aerosols is possible [7]. This type of transmission constitutes a special implication to dentistry as many dental procedures and tools used can induce or generate contaminated aerosols with the potential to cause infection [8]. Dental offices can act as focal spots of cross-contamination and can lead to nosocomial COVID-19 transmission to both patients and dental staff. In fact, a clinical study found that the human-to human hospital related COVID-19 transmission was $41.3 \%, 29 \%$ of which occurred in healthcare workers [9]. Healthcare workers, including dentists and dental staff, who are on the frontline, battling the COVID- 19 pandemic, face an increase in the risk of contracting and transmitting the infection while delivering dental services [10].

COVID-19, which is a highly contagious disease, constitutes a major threat to the health of dentists, their assistants, and patients [11]. There are practical guidelines recommended for dentists and dental staff by the Centers for Disease Control and Prevention (CDC), the American Dental Association (ADA), the World Health Organization and country wise their own association's guidelines are also available to control the spread of COVID-19 [8-10]. These guidelines could contribute, at a population level, in disease control and prevention. Therefore, dentists should have knowledge and awareness of the most effective preventive measures to protect themselves and their patients' health [12]. Given their crucial role in fighting the pandemic, we aimed this study to assess the knowledge, perceptions, and practices of dentists regarding the COVID-19 pandemic in different countries.

\section{Materials and methods}

This cross-sectional study was conducted by a questionnaire consisting of open and close-ended questions in English language created on Google Forms, shared via social media platforms such as WhatsApp and Facebook, to dental professionals worldwide. The study was conducted from 1 June to 31August, 2020 in 14 different countries and regions. Questions were about demographics, perceptions of COVID19 , and practice modifications incorporated in the current pandemic or to combat the spread of COVID19. Demographic questions included age, gender, location, designation, experience in dentistry, and sector of practice. The second section of the questionnaire was regarding the perception of COVID-19 among dental surgeons. The last section of the questionnaire comprised of questions related to practice modifications during the pandemic. The form used in the current study gathered data objectively and validated through the univariate analysis of independent 
variables, while multivariate analysis was done for dependent variables. Any inadequately filled questionnaires were not included in the results of the study. A total of 495 valid respondents of the questionnaire were found after a week of publishing the survey. The participants are from different countries in the south and middle Asia namely, Saudi Arabia, UAE, Pakistan, India, and from other parts of the world.

\subsection{Statistical analysis}

The points allotted for each correct/best answer by participants for a group of questions regarding each component (Knowledge, Perceptions, and Practices) were added/summed to generate an overall score for each of the three components. Mean, standard deviation, and medians were calculated for the overall scores. Frequencies were calculated for categorical variables. Multiple linear regression was used to assess the association of independent variables with the outcome variable, i.e., scores of all three components. A $p$-value of $<0.05$ was considered to be significant.

\section{Results}

\subsection{Univariate analysis}

The univariate analysis results showed that there was a statistically significant association of age, level of practice, and sector of practice with the total knowledge score of participants. Moreover, the total practice score was significantly associated with gender and sector of practice. None of the independent variables was found to be significantly related to total perception scores, given in Table 1 .

\subsection{Multivariable analysis}

Multivariable analysis model using multiple linear regression was formulated by including those variables, which were significant at the univariate stage. Hence, the practice sector was the only variable found to be significantly associated with the total knowledge score $(p$-value $<0.05)$. This infers that estimated mean knowledge scores of dental professionals had an overall decreasing relationship with the sector of practice, showing that those working in the

Table 1

Univariate analysis for the association of dental professionals' COVID-19 knowledge, perceptions and practices with independent variables

\begin{tabular}{|c|c|c|c|c|c|c|c|c|}
\hline \multicolumn{2}{|c|}{ Independent variables } & \multirow[t]{2}{*}{$n(\%)$} & \multicolumn{2}{|c|}{ Knowledge } & \multicolumn{2}{|c|}{ Perceptions } & \multicolumn{2}{|c|}{ Practice } \\
\hline & & & $\begin{array}{c}\text { Mean total } \\
\text { score }(+/-S D)\end{array}$ & $p$ value $\mathrm{e}^{\#}$ & $\begin{array}{c}\text { Mean total } \\
\text { score }(+/-S D)\end{array}$ & $p$-value $\mathrm{e}^{\#}$ & $\begin{array}{c}\text { Mean total } \\
\text { score }(+/-S D)\end{array}$ & $p$-value \\
\hline Age & $\begin{array}{l}20-30 \\
31-40 \\
>40\end{array}$ & $\begin{array}{c}317(64.0) \\
135(27.3) \\
43(8.7) \\
495(100)\end{array}$ & $\begin{array}{l}14.4(+/-2.79) \\
14.9(+/-2.49) \\
15.8(+/-2.92)\end{array}$ & 0.004 & $\begin{array}{l}5.3(+/-2.3) \\
5.2(+/-2.2) \\
5.7(+/-2.6)\end{array}$ & 0.41 & $\begin{array}{l}9.3(+/-1.5) \\
9.5(+/-1.6) \\
9.7(+/-1.7)\end{array}$ & 0.26 \\
\hline Gender & $\begin{array}{l}\text { Female } \\
\text { Male }\end{array}$ & $\begin{array}{l}253(51.1) \\
242(48.9) \\
495(100)\end{array}$ & $\begin{array}{l}14.7(+/-2.6) \\
14.6(+/-2.9)\end{array}$ & 0.77 & $\begin{array}{l}5.1(+/-2.3) \\
5.4(+/-2.2)\end{array}$ & 0.13 & $\begin{array}{l}9.6(+/-1.5) \\
9.2(+/-1.6)\end{array}$ & 0.003 \\
\hline $\begin{array}{l}\text { Level of } \\
\text { practice }\end{array}$ & $\begin{array}{l}\text { General Dentist } \\
\text { Post graduate } \\
\text { Resident } \\
\text { Specialist }\end{array}$ & $\begin{array}{c}328(66.2) \\
89(18.0) \\
78(15.8) \\
495(100)\end{array}$ & $\begin{array}{c}14.5(+/-2.75) \\
15.1(+/-2.6) \\
15.2(+/-2.8)\end{array}$ & 0.05 & $\begin{array}{l}5.2(+/-2.3) \\
5.3(+/-2.1) \\
5.4(+/-2.3)\end{array}$ & 0.89 & $\begin{array}{l}9.3(+/-1.5) \\
9.5(+/-1.7) \\
9.6(+/-1.6)\end{array}$ & 0.36 \\
\hline $\begin{array}{l}\text { Sector of } \\
\text { practice }\end{array}$ & $\begin{array}{l}\text { Government } \\
\text { Private } \\
\text { Semi private } \\
\text { Both Govt } \\
\quad \& \text { Pvt }\end{array}$ & $\begin{array}{c}142(28.7) \\
217(43.8) \\
63(12.7) \\
73(14.8) \\
495(100)\end{array}$ & $\begin{array}{c}14.9(+/-2.4) \\
14.4(+/-2.8) \\
14.1(+/-2.6) \\
15.7(+/-2.9)\end{array}$ & 0.0008 & $\begin{array}{l}5.1(+/-2.2) \\
5.3(+/-2.3) \\
5.1(+/-2.2) \\
5.7(+/-2.5)\end{array}$ & 0.23 & $\begin{array}{l}9.6(+/-1.3) \\
9.2(+/-1.7) \\
9.6(+/-1.8) \\
9.3(+/-1.2)\end{array}$ & 0.03 \\
\hline $\begin{array}{l}\text { Years of } \\
\text { experience }\end{array}$ & $\begin{array}{l}<2 \text { years } \\
2-5 \text { years } \\
>5 \text { to } 10 \text { years } \\
>10 \text { years }\end{array}$ & $\begin{array}{c}82(16.6) \\
134(27.0) \\
135(27.3) \\
144(29.1) \\
495(100)\end{array}$ & $\begin{array}{l}14.3(+/-2.8) \\
14.5(+/-2.6) \\
14.6(+/-2.8) \\
15.1(+/-2.8)\end{array}$ & 0.13 & $\begin{array}{l}5.3(+/-2.2) \\
5.2(+/-2.3) \\
5.3(+/-2.4) \\
5.3(+/-2.3)\end{array}$ & 0.97 & $\begin{array}{l}9.4(+/-1.6) \\
9.3(+/-1.7) \\
9.4(+/-1.3) \\
9.3(+/-1.5)\end{array}$ & 0.89 \\
\hline
\end{tabular}

\footnotetext{
\# Simple linear regression. Overall total mean knowledge score $(n=495)=14.7(+/-2.7)$, median $=15$, range $=7$ to 21 . Overall total mean perceptions score $(n=495)=5.3(+/-2.3)$, median $=5$, range $=1$ to 11 . Overall total mean practices score $(n=495)=9.4(+/-1.5)$, median $=9.5$, range $=4$ to 12 .
} 
Table 2

Multivariable analysis for the association of dental professionals' COVID-19 knowledge, perception and practices with independent variables

\begin{tabular}{|c|c|c|c|c|c|c|c|c|c|c|}
\hline \multicolumn{2}{|c|}{ Independent variables } & \multicolumn{3}{|c|}{ Knowledge } & \multicolumn{3}{|c|}{ Perceptions } & \multicolumn{3}{|c|}{ Practices } \\
\hline & & $\begin{array}{c}\text { B coefficient } \\
(95 \% \text { CI })\end{array}$ & $\begin{array}{c}\text { Standard } \\
\text { error }\end{array}$ & $P$ value ${ }^{\#}$ & $\begin{array}{c}\text { B coefficient } \\
(95 \% \mathrm{CI})\end{array}$ & $\begin{array}{c}\text { Standard } \\
\text { error }\end{array}$ & $P$ value $\#$ & $\begin{array}{c}\text { B coefficient } \\
(95 \% \mathrm{CI})\end{array}$ & $\begin{array}{c}\text { Standard } \\
\text { error }\end{array}$ & $P$ value $^{\#}$ \\
\hline \multirow[t]{3}{*}{$\overline{\text { Age }}$} & $31-40$ & $0.45(-0.095,0.994)$ & 0.28 & $\mathrm{NS}^{* *}$ & $-0.08(-0.54,0.38)$ & 0.23 & $\mathrm{NS}^{*}$ & $0.16(-0.15,0.47)$ & 0.16 & NS* \\
\hline & $>40$ & $1.43(0.56,2.29)$ & 0.44 & & $0.45(-0.28,1.18)$ & 0.37 & & $0.37(-0.13,0.86)$ & 0.25 & \\
\hline & $21-30$ & Reference & & & Reference & & & Reference & & \\
\hline \multirow[t]{2}{*}{ Gender } & Male & $-0.07(-0.56,0.41)$ & 0.25 & $\mathrm{NS}^{*}$ & $0.31(-0.09,0.72)$ & 0.21 & $\mathrm{NS}^{*}$ & $-0.37(-0.65,-0.09)$ & 0.14 & 0.01 \\
\hline & Female & Reference & & & Reference & & & Reference & & \\
\hline \multirow[t]{3}{*}{$\begin{array}{l}\text { Level of } \\
\text { practice }\end{array}$} & $\begin{array}{l}\text { Post graduate } \\
\text { resident }\end{array}$ & $0.61(-0.04,1.24)$ & 0.33 & NS** & $0.04(-0.50,0.58)$ & 0.27 & $\mathrm{NS}^{*}$ & $0.14(-0.22,0.51)$ & 0.18 & NS* \\
\hline & Specialist & $0.69(0.01,1.40)$ & 0.34 & & $0.14(-0.43,0.70)$ & 0.29 & & $0.26(-0.12,0.64)$ & 0.19 & \\
\hline & General dentist & Reference & & & Reference & & & Reference & & \\
\hline \multirow{4}{*}{$\begin{array}{l}\text { Sector of } \\
\text { practice }\end{array}$} & Government & $-0.92(-1.68,-0.15)$ & 0.39 & 0.02 & $-0.66(-1.31,-0.02)$ & 0.33 & $\mathrm{NS}^{*}$ & $0.21(-0.23,0.65)$ & 0.23 & $\mathrm{NS}^{* *}$ \\
\hline & Private & $-1.34(-2.05,-0.63)$ & 0.36 & $<0.001$ & $-0.43(-1.04,0.17)$ & 0.31 & & $-0.20(-0.61,0.21)$ & 0.21 & \\
\hline & Semi private & $-1.66(-2.57,-0.75)$ & 0.46 & $<0.001$ & $-0.59(-1.36,0.18)$ & 0.39 & & $0.18(-0.35,0.71)$ & 0.27 & \\
\hline & $\begin{array}{l}\text { Both govt } \\
\text { and pvt }\end{array}$ & Reference & & & Reference & & & Reference & & \\
\hline \multirow{4}{*}{$\begin{array}{l}\text { Years of } \\
\text { experience }\end{array}$} & $2-5$ years & $0.26(-0.49,1.01)$ & 0.38 & $\mathrm{NS}^{*}$ & $-0.12(-0.75,0.51)$ & 0.32 & $\mathrm{NS}^{*}$ & $-0.13(-0.55,0.29)$ & 0.22 & $\mathrm{NS}^{*}$ \\
\hline & $>5$ to 10 years & $0.36(-0.39,1.11)$ & 0.38 & & $-0.08(-0.71,0.55)$ & 0.32 & & $-0.0006(-0.43,0.42)$ & 0.22 & \\
\hline & $>10$ years & $0.83(-0.09,1.57)$ & 0.38 & & $-0.01(-0.64,0.61)$ & 0.32 & & $-0.09(-0.51,0.33)$ & 0.21 & \\
\hline & $<2$ years & Reference & & & Reference & & & Reference & & \\
\hline
\end{tabular}

*Not significant (NS) at univariate analysis stage. ${ }^{* *}$ Not significant (NS) at multivariable analysis stage. ${ }^{\#}$ Multiple linear regression. 


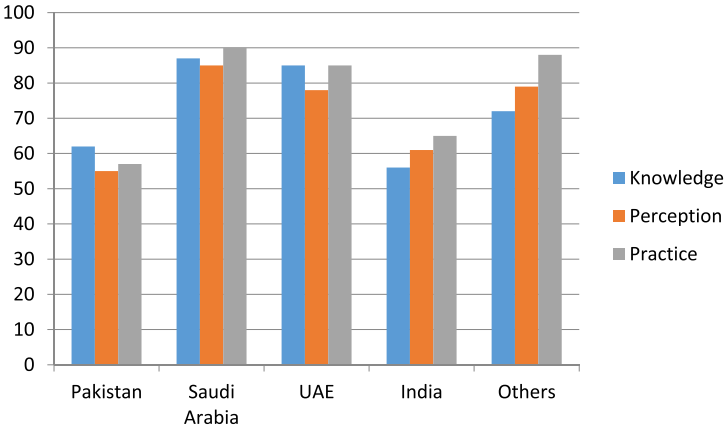

Fig. 1. Country-wise data on knowledge, perception and practice.

government sector $(\mathrm{B}$-coefficient $=-0.92)$ scored significantly better on knowledge assessment than those working in the private sector $(\mathrm{B}$-coefficient $=-1.34$ ) and semi-private sector (B-coefficient $=-1.66)$. Similarly, multivariable linear regression modeling for total practice scores revealed that estimated mean practices score decreases for males by 0.37 units compared to females $(p$-value $<0.05)$, given in Table 2 .

Each country had the different number of participants involved and country-wise data on knowledge, perception and practice is shown in Fig. 1, The dentists had mean score of knowledge regarding disinfection, viability of virus on different surfaces, and proper protective equipment $(n=495)=14.7(+/-2.7)$ for univariate analysis and $0.69(+/-0.39)$ for multivariable analysis $(n=495)$. Thirty six dentists scored a total of 6 out of 10 with only 16 dentists scored $<6$. Most of the dental practitioners had good knowledge about symptomatology of COVID-19 and the prevention of infection.

The majority of dentists had perceived COVID-19 as very threatening, and the mean perception score $(n=495)=5.3(+/-2.3)$ for univariate analysis and $(n=495)=0.69(+/-0.39)$ for multivariable analysis. Most of the dental practitioners reported that COVID19 is a major global health problem and believed that public awareness is necessary regarding COVID-19 to prevent the transmission of the virus.

Several dentists shared that COVID-19 symptoms often resolved with time and do not required any special management. The mean practices score was $(n=495)=9.4(+/-1.5)$ for univariate analysis and $(n=495)=0.69(+/-0.39)$ for multivariable analysis. Concerning dentists' preventive measures in their setup, most of them reported that it was essential to ask patients to maintain a social distance of minimum $2 \mathrm{~m}$ from each other, wear masks in the waiting area, and wash hands before getting into the dental unit to reduce the virus spread, even 24 (11.7\%) reported that this was not required and may exhibited panic.

\section{Discussion}

As this disease was first reported at the end of 2019 , most healthcare workers, especially dental professionals, were unaware of the disease's signs and symptoms [13]. This study described the knowledge, perceptions, practice modifications, and anxiety of getting exposed among the dental community while at work during this pandemic situation. For this reason, a questionnaire comprising of questions (closedended) was administered to collect information about knowledge of this disease, perception, and any modifications during practice to fight the COVID-19 pandemic. Studies based on the questionnaire are recognized for collecting information about contestants' knowledge, perceptions, attitude, and practices. Still, vigilant collection of data and clarification is required [14].

Our univariate and multivariate analysis revealed that it was related to better knowledge, perception, and infection control. Results from other studies reported no association with age $[15,16]$. First, this small difference in results may be partly related to the difference in the questions used to assess dentists' knowledge. Second, we think that the young dentists were more knowledgeable than older ones because given the lack of latest guidelines for dentists locally available, younger dentists who are more familiar with online learning have consulted the international guidelines that have been published on the international health institutions websites earlier since the start of the pandemic [17].

Our study showed that dentists adopt high level of prevention measures in dental clinics during the pandemic including hand hygiene, surface disinfection, use of personal protective equipment (PPE) and taking patient's temperature as a part of the triage process. Our univariate and multivariate analysis reported that good knowledge was related with having high prevention measures index [18].

The differences between regions reflect the timeline in regional outbreaks and the speed with which countries responded to COVID-19. Some countries were better prepared because their healthcare system is well organized according to WHO health care index $[19,20]$ and as they experienced outbreaks in the past; the SARS in Southeast Asia and the West Pacific 
in2003, [21] and MERS in 2012 in the EMRO region. [22]. The outbreak of the disease in Pakistan alerted heath authorities to the seriousness of the disease, leading to immediate suspension of elective dental treatment and confining treatment to emergency care, with subsequent financial impact on dentists [23].

Most of the dentists in the present study had a good perception and positive attitude towards infection control practices, similar to Peng et al.'s [24] findings in China, where $73.8 \%$ of their subjects demonstrated positive attitudes. This is crucial, as the current approach to COVID-19 is to control the routes of infection and to conduct extensive infection prevention and control (IPC) trainings with preventive measures to lower the risk of transmission [24].

Furthermore, extra-oral radiographs such as OPG (orthopantomogram) and CT scan (cone beam computed tomography) should be employed to reduce the disease spread amongdental auxiliaries. The ultrasonic scaling device must be replaced with hand curettes marking to minimize aerosols' spread and production. Globally, all regulating dental associations such as the ADA are recommending dental professionals to operate only emergency dental procedures [25].

Limitations included recall and information bias related to the use of an online self-administered questionnaire was used as survey instrument. The exponential increase in COVID-19 cases in different countries throughout the period of the survey and the frequency in which guidelines and recommendations were published may have contributed to different responses from the same country and region.

\section{Conclusions}

As information about COVID-19 continues to evolve rapidly, further improvement and update would be beneficial to optimally manage patients in this challenging situation. This study determined that majority of dentists had adequate knowledge, perceptions, and practices of COVID-19. The dentists however had a good perception and positive attitude towards infection control practices against COVID19. Our recommendations are that it is important for dental healthcare professionals to adhere to the strictest protocols and the highest quality standards of care consistently while providing services for patients in a safe environment.

\section{Conflict of interest}

The authors declare no conflict of interest.

\section{Funding}

The authors extend their appreciation to the Deanship of Scientific Research at King Khalid University for funding this work through the General Research Project under grant number GRP/366/42.

\section{References}

[1] Du Toit A. Outbreak of a novel coronavirus. Nature Reviews Microbiology. 2020;18(3):123-123.

[2] Cucinotta D, Vanelli M. WHO Declares COVID-19 a Pandemic. Acta Biomed. 2020;91(1):157-60.

[3] Khalid A, Ali S. COVID-19 and its Challenges for the Healthcare System in Pakistan. Asian Bioethics Review. 2020.

[4] Estrich CG, Mikkelsen M, Morrissey R, Geisinger ML, Ioannidou E, Vujicic M, Araujo MW. Estimating COVID19 prevalence and infection control practices among US dentists. The Journal of the American Dental Association. 2020;151(11):815-24.

[5] Guo H, Zhou Y, Liu X, Tan J. The impact of the COVID-19 epidemic on the utilization of emergency dental services. Journal of Dental Sciences. 2020;16.

[6] Bassetti M, Vena A, Giacobbe DR. The novel Chinese coronavirus (2019-nCoV) infections: Challenges for fighting the storm. European journal of clinical investigation, 2020;50(3):e13209.

[7] Wang W, Tang J, Wei F. Updated understanding of the outbreak of 2019 novel coronavirus (2019-nCoV) in Wuhan, China. J Med Virol. 2020;92(4):441-47.

[8] Careddu R, Ciaschetti M, Creavin G, Molina F, Plotino G. COVID-19 and dental practice: overview and protocols during pandemic. Giornale Italiano di Endodonzia. 202016;34(1).

[9] Lee YL, Chu D, Chou SY, Hu HY, Huang SJ, Yen YF. Dental care and infection-control procedures during the COVID-19 pandemic: The experience in Taipei City Hospital, Taiwan. Journal of Dental Sciences. 2020;15(3):369-72.

[10] Zhu N, Zhang D, Wang W, Li X, Yang B, Song J, Zhao X, Huang B, Shi W, Lu R, Niu P, Zhan F, Ma X, Wang D, Xu W, Wu G, Gao GF, Tan W. A Novel Coronavirus from Patients with Pneumonia in China, 2019. New England Journal of Medicine. 2020;382(8): 727-33.

[11] Guo YR, Cao QD, Hong ZS, Tan YY, Chen SD, Jin HJ, Tan KS, Wang DY, Yan Y. The origin, transmission and clinical therapies on coronavirus disease 2019 (COVID19) outbreak-an update on the status. Military Medical Research. 2020;7(1):1-10.

[12] Dhama K, Khan S, Tiwari R, Sircar S, Bhat S, Malik YS, Singh KP, Chaicumpa W, Bonilla-Aldana DK, RodriguezMorales AJ. COVID-19 Disease due to SARS-CoV-2 (Novel Coronavirus). American Journal of Respiratory and Critical Care Medicine. 2020;201(4):P7-P8. 
[13] Sezgin GP, ŞirinoĞlu Çapan B. Assessment of dentists' awareness and knowledge levels on the Novel Coronavirus (COVID-19). Braz Oral Res. 2020;34:e112.

[14] Sarfaraz S, Shabbir J, Mudasser MA, Khurshid Z, AlQuraini AAA, Abbasi MS, et al. Knowledge and attitude of dental practitioners related to disinfection during the COVID-19 pandemic. Healthcare. 2020;8(3):232.

[15] Hleyhel M, Haddad C, Haidar N, Charbachy M, Saleh $\mathrm{N}$. Determinants of knowledge and prevention measures towards COVID-19 pandemic among Lebanese dentists: a cross sectional survey. BMC Oral Health. 2021;21(1):1-9.

[16] Induri SN, Chun YC, Chun JC, Fleisher K, Glickman R, Wu F, Ioannidou E, Li X, Saxena D. Protective Measures Against COVID-19: Dental Practice and Infection Control.

[17] Samaranayake LP, Peiris M. Severe acute respiratory syndrome and dentistry: a retrospective view. J Am Dent Assoc. 2004;135(9):1292-302.

[18] Sukumaran A, Patil S. The MERS-CoV outbreak: challenges facing the dental profession. J Contemp Dent Pract. 2014;15(2):i-ii.

[19] Tandon A, Murray CJ, Lauer JA, Evans DB. Measuring overall health system performance for 191 countries. Geneva: World Health Organization. 2000. https://www. numbeo.com/health-care/rankings_by_country.jsp

[20] Bakaeen LG, Masri R, AlTarawneh S, Garcia LT, AlHadidi A, Khamis AH, Hamdan AM, Baqain ZH. Dentists' knowledge, attitudes, and professional behavior toward the COVID-19 pandemic: A multisite survey of dentists' perspectives. The Journal of the American Dental Association. 2021;152(1):16-24.

[21] Peng Y, Pei C, Zheng Y, Wang J, Zhang K, Zheng Z, Zhu P. Knowledge, attitude and practice associated with COVID19 among university students: a cross-sectional survey in China.

[22] Umeizudike KA, Isiekwe IG, Fadeju AD, Akinboboye BO, Aladenika ET. Nigerian undergraduate dental students' knowledge, perception, and attitude to COVID-19 and infection control practices. Journal of Dental Education. 2021;85(2):187-96.

[23] Peng X, Xu X, Li Y, Cheng L, Zhou X, Ren B. Transmission routes of 2019-nCoV and controls in dental practice. Int J Oral Sci. 2020;12(1):9.

[24] Beltrán-Aguilar E, Benzian H, Niederman R. Rational perspectives on risk and certainty for dentistry during the COVID-19 pandemic. American Journal of Infection Control. 2021;49(1):131.

[25] Jamal M, Shah M, Almarzooqi SH, Aber H, Khawaja S, El Abed R, Alkhatib Z, Samaranayake LP. Overview of transnational recommendations for COVID-19 transmission control in dental care settings. Oral Diseases. 2021;27: 655-64. 